\title{
“COMIDA RÁPIDA, IGUAL O RODÍZIO DE ATENDENTES”: NARRATIVAS \\ DE EX-FUNCIONÁRIOS/AS DE UM RESTAURANTE FAST-FOOD
}

\author{
Aline dos Santos Carolino ${ }^{1}$
}

\section{Introdução}

A partir do viés antropológico, este artigo tem como objetivo analisar as narrativas de ex-funcionários/as de um restaurante fast-food. Considerando o processo de produção da comida; as relações que se criam no estabelecimento: entre funcionários/as e entre funcionários/as e o lanche; as dificuldades como: a precariedade do ambiente e o esgotamento emocional. Suas narrativas são analisadas a partir dos textos lidos na disciplina de Antropologia da Alimentação ${ }^{2}$, com foco na alimentação na modernidade e a etnografias feitas em restaurantes fast-food.

\subsection{Metodologia}

Esta pesquisa é fruto de entrevistas com ex-funcionários/as de um restaurante fast-food e revisão bibliográfica sobre o tema. Os nomes dos/as ex-funcionários/as são mantidos em anonimato, sendo eles/as identificados pelos nomes fictícios: Eli e Santana, suas idades são mantidas na realidade. O nome da rede de restaurantes fastfood, na qual trabalharam, é mantida em anonimato. Isto a pedido de ambos/as os/as interlocutores. É utilizado o itálico para destacar as palavras nativas, nem sempre seguidas de explicação, propondo que o/a leitor/a vá se ajustando as categorias.

A pesquisa estrutura-se, inicialmente, com um levantamento de textos a respeito do cenário da pesquisa, como se constituiu os primeiros restaurantes fast-food; quem foram os precursores; como é a funcionalidade atualmente. Na sequência há uma reflexão sobre o ritmo de preparo e o adestramento dos/as ex-funcionários/as, no cumprimento das atividades impostas pelo estabelecimento. Em seguida, é abordada a

\footnotetext{
${ }^{1}$ Universidade Federal de Santa Catarina, Brasil. Email: carolinoaline8@gmail.com ORCID id: https://orcid.org/0000-0002-3433-5592

${ }^{2}$ Disciplina ministrada para o curso de Antropologia, no segundo semestre de 2018, pela professora Dra. Juliana Cavilha Mendes Losso. Pós-doutorada em Antropologia Social e professora substituta na Universidade Federal de Santa Catarina (UFSC/Florianópolis).
} 
visão dos/as ex-funcionários/as sobre os/as clientes, quem era o público alvo; como era a relação funcionário/a e cliente. Por último é desenvolvida uma reflexão sobre a precariedade do trabalho, os impactos emocionais e as dificuldades de permanência.

\section{Contextualização do cenário da pesquisa}

Nas últimas décadas, o hábito de "comer fora de casa" tornou-se cada vez mais comum, trazendo modificações em nossos padrões alimentares tradicionais. Atualmente temos diversos meios de encontrar restaurantes com alimentos que são produzidos em um intervalo curto de tempo. Fast-food significa comida rápida, em que a rapidez e o padrão de atendimento são garantias que atraem os clientes. Conforme Rial (1997: 4) "[Fast-food] são grandes cadeias de lanches rápidos que se organizam num sistema de franquia, empregam técnicas tayloristas e fordistas ${ }^{3}$ na preparação culinária e dedicam boa parte de sua renda à publicidade". Cascudo (1983 [1963]) citado por Gonçalves (2004) escreve que no mundo moderno as refeições não desaparecem, mas tendem a ser substituídas por práticas alimentares ocasionais, irregulares e ligeiras, em suas palavras:

Restaurantes e locais de venda da chamada fast-food substituem o espaço da comida feita em casa. Relações sociais e culturais são substituídas por necessidades imediatas. $\mathrm{O}$ apetite e o paladar perdem espaço para a fome. Nutricionistas ocupam o lugar dos cozinheiros tradicionais. Comidas enlatadas substituem longos e complexos processos de preparação de alimentos. Comportamentos casuais, barulhentos e apressados competem com o ritmo lento e silencioso das refeições tradicionais (p. 47).

Atualmente, além das redes tradicionais surgiram outras categorias fast, com o pedido via aplicativo de celular e a entrega em casa. Mas ainda assim, há uma massa de pessoas que fazem suas refeições em praças de shopping centers e em restaurantes fastfood espalhados pelas cidades. À medida que "o modelo fast-food transformou-se em um sinônimo de estilo de vida, em que o tempo é exíguo até mesmo para a realização das refeições" (Reis e Arend, 2009: 143). Rial (1997: 6) exprime que os "fast-foods surgiram na Califórnia, no pós-guerra, em 1940, nos anos que marcaram o auge da indústria cinematográfica americana". Os irmãos McDonald's: Rick e Maurice, precursores no uso de publicidade em restaurantes, revolucionaram a cadeia ao abrirem uma lanchonete que vendia hambúrgueres por 10 centavos cada, servidos de minuto a

\footnotetext{
${ }^{3}$ Esses dois sistemas visavam a produção em massa para a maximização do lucro.
} 
minuto, embrulhados em papel e sem necessidade de garçons: o cliente fazia o pedido diretamente ao cozinheiro. Foi trazida para esta cozinha a divisão taylorista do trabalho, como Santos (2006: 4) aponta "para tanto, implantaram uma planificação na cozinha, compartimentando o processo de produção que passou a ser executada por uma equipe reduzida de mão-de-obra, mal assalariada, e sem grande qualificação profissional”. Acentuando que o preparo das refeições se dava a partir de produção em cadeia ${ }^{4}$.

O país vivia toda a pujança da indústria e iniciava a escalada da sociedade de serviços, com seus horários e demandas que iam muito além do expediente nine-to-five. Com pouco tempo para o almoço, com grande probabilidade de ter de "devorar" a comida no próprio ambiente profissional, eis que então surgiu a conveniência dos “sandubas" rápidos, das "fritas" sempre quentes. Silva (2006: 8) aponta que "a indústria agroalimentar e a distribuição em larga escala invadiram a Europa em meados de 1970, baseada em um modernismo alimentar". O caráter tido como exótico do fast-food surpreendeu pela sua originalidade, pela sua diferença, por não ser familiar.

No Brasil o fundador do Bob's, Robert Falkenburg, introduziu o fast-food em 1952, em Copacabana. A primeira entrada estrangeira no Brasil veio somente em 1979, com a abertura da primeira loja do McDonald's, também em Copacabana. A cadeia de lojas McDonald's foi crescendo cada vez mais e, como ela, outras cadeias de lojas de refeições rápidas, como Subway; McDonald's; Bob's; Burguer King; Habib's; Giraffas; Spoleto; Pizza Hut, entre outras.

Conforme Favoretto e Wiernetz (2013: 4) "A indústria "fast food" movimenta US\$ 120 bilhões nos Estados Unidos, com cerca de 200.000 restaurantes em funcionamento". Dentre as principais cadeias de restaurantes, metade são lanchonetes baratas que vendem hambúrgueres. Em conformidade com a pesquisa de Dora (2016): “O gasto com fast food por habitante no Brasil, em 2014, foi de 265 reais, o consumo deve crescer em 30,88\% até 2019”. Estes restaurantes, atualmente, têm como preferência a contratação de jovens para o atendimento. Reis e Arend (2009:143), no texto "Juventude e restaurantes fast food: a dura face do trabalho flexível" apontam que no Brasil, as taxas de desemprego entre jovens de 16 a 24 anos são dramáticas, "a indústria de fast-food aparece como importante gerador de empregos para esse exército de mão de obra excedente".

${ }^{4}$ É importante acentuar que tal funcionalidade do processo de produção taylorista foi magistralmente criticada por Charles Chaplin, no antológico filme "Os Tempos Modernos” (SANTOS, 2006: 4). 
Nos tópicos abaixo é elucidado como é esse trabalho pela visão dos/as exfuncionários/as.

\section{Ritmo: o adestramento dos/as ex-funcionários/as}

As redes de fast-food são caracterizadas pela natureza de competitividade e grande pressão sobre os/as funcionários/as no que se refere a produtividade. Allan, et al (2001:) citado por Gorzoni (2010: 39) apontam que “os salários são abaixo da média, condições de trabalho inadequadas, pouco treinamento, poucas chances de crescimento profissional, altas taxas de rotatividade e supervisão rigorosa". Sendo um ambiente que tem como pré-requisito, a contratação de jovens entre 16 a 24 anos. No que diz respeito aos jovens aqui entrevistados/as, trabalhadores da indústria de fast-food, ambos/as seguem a regra exigida pela empresa para ocupar a vaga. Eli, de 18 anos (entrevistado/a em 03/10/2018), indica, na entrevista gravada, que a sua relação com a cozinha era difícil e cansativa,

O ritmo com essa cozinha era cansativo, tinha que tomar conta da carne, porque se tivesse acabando tinha que ativar mais. Tinha que condimentar os lanches que estavam saindo, pegar o pão e ver o abastecimento, depois a salada. Tudo de uma hora para outra. O movimento não é constante, ele do nada está parado, dois minutos depois um monte de gente. Tudo isso sob os olhos do gerente (Grifos meus).

O ritmo no preparo e a agilidade são fundamentais. Para efetuar o trabalho é preciso fazer diversas atividades ao mesmo tempo, como: tomar conta da quantidade de carne, para que nunca falte na panela; condimentar os lanches que estão saindo; ao pegar pão, ver se a bandeja precisa ser reabastecida; sendo o mesmo procedimento repetido diversas vezes ao longo do dia. A noção de ritmo evoca a "nova" sociedade de trabalho, onde são pautadas pelas novas tecnologias, novas relações de trabalho, conforme Santos (2006: 3) "os ritmos e as velocidades da vida se aceleram de forma jamais vistas, impondo mudanças culturais que implicam numa certa submissão na forma de ver, pensar, imitar e agir”. Montanari (2008: 60), em sua obra Comida como cultura, desenvolve que a cozinha é um conjunto de técnicas, dirigidas a preparação do alimento. Nos países industrializados o conjunto de técnicas necessárias, segundo o autor, "para a preparação das comidas corriqueiras é muito limitado e rápido, dado que 
muitas incumbências preliminares são executadas por profissionais e pela indústria agro alimentícia".

Já Marcel Mauss (1934), em seu texto As técnicas do corpo relaciona as noções, de "trabalho duro" e "conjunto de técnicas", na qual as técnicas do corpo são equivalente ao rendimento, partindo desse viés, podemos olhar as atividades realizadas pelos/as os/as funcionários/as desta forma, onde passam por um adestramento do corpo ao trabalhar no restaurante fast-food, o autor é bastante esclarecedor ao escrever que "o adestramento, como a montagem de uma máquina, é a busca, a aquisição de um rendimento. Aqui, é um rendimento humano. Essas técnicas são, portanto, as normas humanas do adestramento humano" (MAUS, 1934: 410). Essa característica de "trabalho duro" no fast-food, consta na descrição etnográfica de Rial (1997), no texto Os fast-foods uma homogeneidade contestável na globalização cultural, de forma semelhante a que está sendo analisada aqui, ela aponta que:

\begin{abstract}
Se mostrava, desde o início, assustador, dada a imposição de um ritmo e de uma cadência histérica ("Em dois minutos, um équipier do McDonald's deve preparar 12 hamburgers ou 10 pacotes de fritas"). "É preciso elaborar as fritas", dizia brincando à colega que passava comigo intermináveis horas no Quick, fritando batatas, recolhendo bandejas e, sobretudo, ouvindo gritos dos chefes (1997: 3).
\end{abstract}

O ritmo acelerado e o controle do cumprimento dos procedimentos pelos/as gerente caracterizavam uma organização rígida, fato que contribuiu para o desgaste, estresse e alta rotatividade dos/as atendentes. ${ }^{5}$ Os gerentes, de acordo com Gorzoni (2010: 28) "são responsáveis pelo controle e supervisão e dispõe de grande poder institucional, fato que inibe a contestação de ordens e decisões por parte dos atendentes". Santana (entrevistado/a em 02/09/2018). expôs que nos momentos em que o restaurante estava cheio os/as trabalhadores eram submetidos a um ritmo insustentável, no entanto, não era sempre assim, havia momentos de descontração, onde os/as funcionários/as podiam conversar e brincar. Breves momentos de "liberdade", de fuga do ritmo e da padronização, mas como Eli relata "se mexíamos no celular, eles já pediam para voltar".

\title{
3. O público-alvo
}

\footnotetext{
${ }^{5}$ Segundo Di Pietro e Pizam (2008) Neste sentido, faz-se necessário observar que o segmento de fast-food é, atualmente, um dos que apresenta uma das maiores taxas de rotatividade de funcionários/as, principalmente nos Estados Unidos (apud GORZONI, 2010: 28). No Brasil, não se acredita que seja diferente, porém não há dados oficiais disponíveis.
} 
Grisolia e Castro (2016) escrevem que a produção no restaurante fast-food é racionalizada e obedece aos preceitos do taylorismo-fordismo. Em alguns restaurantes a linha de montagem se desdobra a frente do cliente, onde ele também faz parte deste procedimento. Em algumas redes a comida é preparada na cozinha, podendo ser vista através do balcão, em outras, o procedimento é feito por intermédio do cliente, segundo os autores, de forma semelhante ao narrado pelos/as interlocutores: "o funcionário atende ao cliente sempre da mesma forma, com o mesmo cumprimento inicial, sorriso no rosto e polidez" (: 218). Conforme ao relato de Santana, de 18 anos que trabalhou no estabelecimento durante um ano e meio, o alimento passava pelas seguintes etapas: aquecer; juntar os ingredientes e entregar:

Há uma estimativa de tempo para essa produção, este tempo está dentro da estimativa de tempo de espera do cliente: 1 minuto no caixa, 1 minuto na fila e 2 minutos de espera. Sendo 4 minutos de atendimento por cliente.

O público alvo era quem tinha dinheiro. A obrigatoriedade do/a funcionário/a era vender o máximo ao cliente e com o adicional. O adicional, de acordo com os/as exfuncionários/as, é o ato de colocar algo a "mais" no lanche, na batata frita, no sorvete. Por exemplo, quando o cliente compra um sorvete, é dever do/a funcionário/a perguntar se este/a quer mais cobertura; amendoim; granulado; entre outros complementos. Eli ressaltou que:

Sempre tinha que ter a mais, tínhamos que sempre vender mais do que o cliente estava pedindo (18 anos).

A maioria dos/as clientes, para eles/as, eram "visivelmente" acima do peso, e, estavam nas filas, de algum dos restaurantes do shopping, todos os fins de semana, ou ao longo da semana. Os/as adolescentes também eram um grande público-alvo. Considerando que o shopping é um ambiente que os/as instiga a comparar na praça de alimentação. Onde, de acordo com Santos (2006: 10) "esta praticidade e rapidez imposta pela sociedade contemporânea acabam derrubando as convenções ditas pela sociedade, construídas historicamente e pautadas pela tradição e pelos costumes”. Eli narra que, para estimulá-los ainda mais, criavam promoções de milkshake. Essas ofertas eram anunciadas no telão do estabelecimento, sendo por tempo limitado. Como aponta o/a funcionário/a:

Os gerentes diziam, tem mais cliente na outra loja, vamos fazer alguma coisa para atrair os clientes. As vezes queriam que fossemos no meio do shopping 
chamá-los. Se não batíamos a meta a culpa era nossa. Se o cliente não queria adicional, queriam que a gente insistisse. Eles tiveram uma ideia, de que se a gente vendesse cinquenta adicionais no dia, ganhava uma casquinha. Essa era a recompensa. Se batêssemos três metas ganhávamos um sunday. Se batesse todas as metas ganhávamos um milkshake pequeno. Criaram isso para a gente se sentir um pouco reconhecido (Eli, 18 anos).

A necessidade de dar atenção para o cliente era fundamental. Caso não acontecesse, geravam-se conflitos entre atendente e o/a cliente e, nestes casos, para o gerente, a culpa nunca é do cliente. Conforme a narrativa de Santana:

Tinha muito cliente ignorante, principalmente no fim do dia, faltava um ingrediente, já colocavam a culpa em nós, sendo que, na maioria das vezes, não era nossa culpa. Um lanche errado as vezes é falta de comunicação. Não há monitor dentro da cozinha, então quem estava no caixa tinha que gritar para o cozinheiro qual era o lanche, as vezes a comunicação acabava se perdendo (18 anos).

Ambas as interlocutoras, entrevistas em dias diferentes, também apontaram que, muitas vezes, os clientes faziam com que se sentissem envergonhados/as por trabalhar no restaurante, pois, muitos deles, os/as viam como pessoas que não tem estudos e que não possuem capacidade de melhorar de vida. Como podemos depreender das narrativas dos/as ex-funcionários/as:

As pessoas pensam que não temos estudos, que não somos ninguém. Sempre vejo pessoas compartilhando nas redes sociais piadas sobre trabalhadores de fast-food. Eu vejo com um trabalho digno como qualquer outro. É um trabalho bom, tem seus prós e contras, mas eu "cresci" muito ali dentro, aprendi a ter responsabilidade. Foi bom para mim, por muito tempo. Mesmo que a rotina fosse ruim, eu sabia de onde estava, o que fazer (Santana, 18 anos).

Acham que só porque eu trabalhava ali não era ninguém na vida. Um dia estava no quiosque, passou um grupo de pessoas, dizendo e apontando: "pelo menos não trabalho ali (Eli, 18 anos).

Isso mostra, que, o desgaste emocional e físico, vai além do trabalho cansativo. Os/as ex-funcionários/as eram alvos de ataques, daqueles que, muitas vezes, consomem o produto.

\section{A precariedade e o "espírito de competição".}

O horário de almoço é a primeira dificuldade apontada nas narrativas dos/as exfuncionários/as. Cada funcionário/a tinha uma hora para almoçar, entretanto, a comida não era da sua escolha. Era obrigatório comer na "praça de alimentação" um lanche vendido no estabelecimento. Assim, Eli narra que: 
Tínhamos direito a cem gramas de carne, que era dois lanches pequenos com uma carne; um lanche grande com uma carne ou um lanche pequeno com duas carnes. A sobremesa era sorvete ou batata-frita. E $500 \mathrm{ml}$ de refrigerante (18 anos).

Para ele/a, essa alimentação causou ansiedade e descontrole alimentar. Sobre esse tema, Silva (2009: 11) escreve que "No Brasil, os estudos e pesquisas têm demonstrado que, em função do Fast-Food [sic], um novo padrão alimentar está se delineando, com prejuízos dos produtos da dieta tradicional do povo". Do mesmo modo em que, no texto Dos riscos alimentares à gestão da ansiedade, Jean-Pierre Poulain (2004: 103) considera que ao comer ingerimos algo que participa da nossa vida corporal intima, em suas palavras, "ele atravessa a fronteira entre nós e o mundo. Ele nos reconstrói e nos transforma ou pode nos transformar. É por isso que a alimentação nos dá de uma certa maneira o sentimento de "controle de nossa vida cotidiana". Por não servirem uma alimentação nutritiva, os hábitos alimentares de ambos/as os/as exfuncionários/as se descontrolaram. Neste sentido Silva (2009: 11) reflete que "o arroz, feijão, a farinha de mandioca, que foram, desde o século XVIII, a base do cardápio da maioria da população, perdem cada vez mais espaço para os produtos industrializados e com maior valor agregado". Ao ingerir este estilo de vida e, além de conviver com a preparação do fast-food, Santana exprimiu que, quando chegava em sua casa, não tinha apetite para outros alimentos:

Não conseguia sentir o gosto de outras carnes, somente a carne industrializada e gordurosa do fast-food. Viciei de tal forma, sempre queria mais" (18 anos).

No entanto, não tinha como fugir desse hábito, onde, de certa forma, o/a interlocutor/a deixa implícito, de forma semelhante ao que Reis e Arend (2009: 143) escrevem sobre o trabalho nos grupos sociais brasileiros de baixa renda, na qual "é um meio de garantir a sobrevivência, bem como um caminho para melhora das condições de vida" Sendo um ambiente que, conforme o/a interlocutor/a relata:

Tinha que "andar na linha", comer o que eles davam, pois como a comida é rápida o rodízio de atendentes também é. $\mathrm{O}$ trabalho é rotineiro. $\mathrm{O}$ medo de ser substituído sempre está presente, não conseguia me sentir efetivada lá (Santana, 18 anos).

Ao mesmo tempo que é um trabalho cansativo é um trabalho "fácil" de aprender, assim Eli aponta que qualquer um que entrasse conseguiria realizar. Para a rede, o que importa, é o cargo estar ocupado: 
Com o tempo fui percebendo que não fazia diferença eu estar ali ou não; não era por conta do salário; da carga horária, mas pelo que fazemos, quem trabalha ali não se sente nem um pouco valorizado" (Eli, 18 anos).

O sistema também criava o "espírito de competição" entre os/as funcionários/as e entre os turnos, de dia e de noite. As competições eram de venda, como já mencionado, do adicional; dos hambúrgueres do mês ou milkshake. Santana pontua que o fluxo de clientes, do turno da noite, era maior. O turno da manhã tinha poucas chances de vender a mais e ganhar as competições, fazendo com que, segundo eles/as, o gerente exercesse mais pressão no turno da manhã, do que no turno da noite. Esse sistema, se estendia entre os/as funcionários/as do mesmo turno, no que se percebe na seguinte narrativa:

\begin{abstract}
Para ser funcionário revelação é complicadíssimo porque tem que seguir todos os padrões, todos as regras, ninguém fazia isso. Ninguém conseguia seguir todas as regras, essa pessoa podia até ganhar de funcionário do mês, mas todos sabiam que tinha deixado muita coisa nas "costas" dos outros. Aconteceu várias vezes no turno da manhã. Não era todo mundo excelente no que fazia. Para seguir todas as regras e padrões, acabava atrasando o trabalho dos outros. $\mathrm{O}$ gerente via o trabalho desta pessoa que estava pronto, mas o meu, por exemplo não estava. Gerava mais conflitos. Trabalhávamos de forma rude um com o outro por causa dessas competições. Até hoje existe isso lá dentro, mantenho contato, quando vou lá converso com meus ex-gerentes e a gente acaba sabendo o que acontece lá (Eli, 18 anos).
\end{abstract}

A fala de Eli e Santana são comentários sobre a competição que o estabelecimento cria para conseguir mais aproveitamento dos/as funcionários/as. Para ambos/as isso gerava conflitos e insatisfação de um/a funcionário/a com o/a outro/a e entre turnos. As narrativas, ainda apontam que vários dos/as atendentes, que venciam nas competições, ficavam com mais expectativas de prosseguir no caminho das promoções. Assim, não se importavam com os/as outros/as funcionários/as, só queriam chegar no objetivo.

Um/a dos/as interlocutores ressaltou que no seu turno trabalhavam cinco funcionários/as divididos em cinco áreas. Cada dia era uma nova função, conforme ele/a:

Segunda era minha folga; terça eu era cozinha; quarta eu era caixa; quinta eu era balcão; sexta eu era quiosque; no sábado fazíamos um sorteio e no domingo cada um decidia para que área queria ir, sempre tinha briga para ir pro quiosque (Santana, 18 anos). 
Segundo eles/as o quiosque era um ambiente inóspito e precário, por não ter companhia de outro/a funcionário/a; ser um local pequeno e não ter, durante oito horas, um lugar para sentar-se.

\section{Considerações Finais}

Em síntese conclui-se que para ambos/as os/as ex-funcionários/as, trabalhar no restaurante foi uma experiência difícil, uma vez que forneceu poucas opções de melhoria de cargo; insatisfação emocional e instabilidade. A rede de fast-food esperava que eles incorporassem a agilidade e a presteza na produção do produto e do serviço, adquirindo a noção de ser fast.

Ambos/as pontuam que o trabalho não dava condições de melhoria de cargo; pouco treinamento para realizar as atividades, assim como alta taxa de rotatividade, passando aos funcionários/as a sensação de que, a qualquer momento, poderiam ser substituídos.

O ritmo de trabalho para os jovens funcionários/as era pautado na observação massiva do gerente e, com isso, era necessário efetuar várias atividades ao mesmo tempo. Considerando que para tudo há um tempo e, este tempo, é o tempo do cliente, que não pode ficar insatisfeito. $\mathrm{O}$ estabelecimento esperava dos/as funcionários/as rendimento; este rendimento só se efetiva, a partir do adestramento rotineiro do corpo humano. Para eles/as os momentos de "fuga" da cozinha era quando havia pouco movimento, nesta breve sensação de "liberdade", eles/as podiam conversar e interagir.

Como são jovens entre 16 a 24, há a visão de que podem suportar uma disciplina com uma extenuante carga de trabalho. Os/as interlocutores também pontuaram que foram alvo de piadas e injúrias diversas vezes, somando para o desgaste físico e emocional. Esse estresse se adicionava a falta de uma alimentação saudável e o "espírito de competição" presente no estabelecimento.

\section{REFERÊNCIAS}


AREND, Sílvia M. F.; REIS, Antero M. D. Juventude e restaurantes fast food: a face dura do trabalho. Rev. katálysis, Florianópolis, v. 12, n. 2, p. 142-151, dezembro de 2009.

Disponível: $\quad<$ http://www.scielo.br/scielo.php?script=sci_arttext\&pid=S1414$49802009000200003 \& \operatorname{lng}=$ en\&nrm $=$ iso $>$.

FAVORETTO, Célia M.; WIERNETZ, Patrícia L. Alimentação sustentável e alimentos de fast food: o que a química e o meio ambiente têm a ver com isso? Os desafios da escola pública paranaense na perspectiva do professor PDE. 2013. Disponível: http://www.diaadiaeducacao.pr.gov.br/portals/cadernospde/pdebusca/producoes_pde/20 13/2013_uepg_qui_artigo_celia_mara_favoretto.pdf

GONÇALVES, José R. S. A fome e o paladar: a antropologia nativa de Luís da Câmara Cascudo. Estudos Históricos. 2004.

GORZONI, Patrícia M. Cultura organizacional e qualidade de vida no trabalho: um estudo com funcionários de um restaurante fast-food. 2010. Dissertação de mestrado (Engenharia de Produção) - Escola de Engenharia de São Carlos da USP. Disponível em:

http://www.teses.usp.br/teses/disponiveis/18/18157/tde-25112010-091200/en.php.

GRISOLIA, Felipe S.; CASTRO, Lucia R. D. A padronização no fast-food e seus efeitos na subjetividade do jovem trabalhador. Gerais, Rev. Interinst. Psicol., Juiz de fora, v. 9, n. 2, p. 211-226, dez. 2016 . Disponível em $<$ http://pepsic.bvsalud.org/scielo.php?script=sci_arttext\&pid=S1983-

$82202016000200005 \& \operatorname{lng}=$ pt\&nrm=iso $>$

MAUSS, Mauss [1934] As técnicas do corpo In Sociologia e Antropologia, Cosac Naify, 1934.

MONTANARI, Massimo. Comida como cultura: Fogo, cozinha e civilização. 1. ed. Senac. 2008. 208 p.

POULAIN, Jean. P. Dos riscos alimentares à ansiedade. In: Sociologia da Alimentação: os comedores e o espaço social alimentar. Fpolis, ed. UFSC, 2004. pg. 23 $-40$

SANTOS, Carlos Roberto Antunes dos. O império McDonald e a McDonalização da sociedade: alimentação, cultura e poder. 2006.

RIAL, Carmen S. M. Os fast-food uma homogeneidade contestável na globalização cultural. Horizontes Antropológicos Diferenças Culturais vol. 5, p.140180, julho 1997 em Antropologia em Primeira Mão, PPGAS/UFSC, 1995.

Recebido 24/09/2019

Aprovado 11/12/2019 